\title{
Investigation of Hydroabrasion in Slurry Pipeline Elbows and T-junctions
}

\author{
Mehdi Azimian and Hans-Jörg Bart \\ Chair of Separation Science and Technology, University of Kaiserslautern, Kaiserslautern D-67663, Germany
}

Received: June 17, 2013 / Accepted: August 06, 2013 / Published: January 31, 2014.

\begin{abstract}
The present study demonstrates the comparison of erosion rate of critical pipeline parts, namely elbow and T-junction which face the maximum erosion in a pipeline and may cause an early damage and failure of the system. CFD (computational fluid dynamics) with an Eulerian-Lagrangian approach coupled with an approved erosion model is applied to visualize the 3-D flow behavior of slurry flow in both parts and to predict the erosion rate and the location of erosion at the internal surfaces. The analysis of slurry erosion is performed in five steps; geometry and grid generation, grid study/refinement, fluid flow solution, solid particles tracking and finally, the erosion calculation. In previous publications in literature considering transportation of gas-solid flows in pipe parts, the application of T-junctions instead of elbows for specified conditions in order to reduce the erosion is recommended. In this article, it is approved that for liquid-solid flows, the Stokes number is reasonably smaller than the values for gas-solid flows. This causes the solid particles tightly couple to the fluid phase and to travel more closely with the fluid streamlines. The effects of important influencing parameters such as feed flow velocity, solid concentration, particle size and shape are investigated in detail in current work. It was found that for liquid-solid flows, the erosion of T-junction for all of the mentioned influencing parameters, due to its geometrical specifications and Stokes number variation in comparison with gas-solid flows, is reasonably higher than erosion of elbow. Due to these findings, in contrary to the gas-solid mixture flows, application of T-junction instead of elbow for liquid-solid flow transportation is not recommended.
\end{abstract}

Key words: CFD, liquid-solid mixture flow, elbow and T-junction, erosion rate.

\section{Introduction}

Hydro-erosion occurs in practice in two ways; one is the erosion by a cavitating liquid and another is the erosion by solid particles entrained in liquid flow known as slurry flow [1]. In the flows of liquid-solid mixtures (two-phase flows), the material removal from the equipment components is mainly caused by the solid particles and the material loss caused by corrosion is relatively minor. Some of application examples are in processing technology such as stirrers in flotation cells for the wet metal processing or pumps for water treatment, mining and smelting industry, pipes in materials handling with hydraulic contaminant of grained solids (sand, coal, emery, ore, fly ash) and

Corresponding author: Hans-Jörg Bart, Prof. Dipl.-Ing. Dr. techn., research fields: extraction and multiphase flows. E-mail: bart@mv.uni-kl.de. turbines and control devices in hydropower engineering, especially with high water amount or exposed to flooding. The solid concentration for example in the hydraulic coal production reaches values up to approximately 65 weight $\%$. However, the solid particle concentration in industrially used pumps is significantly lower. The solid contents for well water with $0.3 \mathrm{ppm}$, oil wells with $6 \mathrm{ppm}$ to $600 \mathrm{ppm}$ (peak values 3,000 ppm) and for glacier water with $500 \mathrm{ppm}$ (peak values 2,500 ppm) are given in Ref. [2]. Material removal due to solid particle erosion can also be desirable such as in abrasive jet micromachining in which a jet of small particles is used to form each component for use in micro-electromechanical systems and microfluidic components. In the most of practical applications, a large number of irregular particles are present in the abrasive jet. However, the study of the 
impact of single particles with a known geometry is nevertheless very useful to understand the fundamental mechanisms of material removal and to determine the rebound kinematics of particles and collision effects on the erosion process [3].

The material removal is determined by the laws of fluid mechanics and properties of the liquid-solid mixture and the target material properties. The flow properties are dependent of the component geometry, surface topography and flow rate. Moreover, the physical properties of the two-phase mixture are affected by the solid particle concentration, size distribution, type, shape, density, hardness and particle settling velocity. Various conditions in the flow fields lead to different solid motions. In pipes, the solid phase concentration will increase with decreasing flow velocity over the pipe cross-section due to increasing the influence of gravity, which set a continuous transition from quasi-homogeneous state to the phase separation with the standstill of the solid particles. For a safe and economic flow transport, in order to take off any solid particles at rest, a turbulent flow with a minimum velocity in long distance pipelines from 1.5 $\mathrm{m} / \mathrm{s}$ to $2.2 \mathrm{~m} / \mathrm{s}$ [4] and from $0.5 \mathrm{~m} / \mathrm{s}$ up to $5 \mathrm{~m} / \mathrm{s}$ [5] should be provided. This means that the flow rate must be matched to the settling velocity of the solid particles.

For flow redirections in pipelines, elbows and T-junctions are applied as common geometries as depicted in Figs. 1a and 1b, respectively. Both elbows and $\mathrm{T}$-junctions are susceptible to erosion when abrasive solid particles are present in the flow. As depicted in Fig. 2, the solid particles due to their higher density are exposed to a stronger centrifugal force than the surrounding liquid and thereby are moving down along a curved path to the outer wall. Compared to a straight pipe flow, in a bend or elbow due to the decomposition occurrence, a relatively small surface element of the wall is faced more severe to the solid particles, resulting in formation of wear in the form of a wear hollow which eventually leads to the breakthrough of the wall. In this article, it was found that the wear

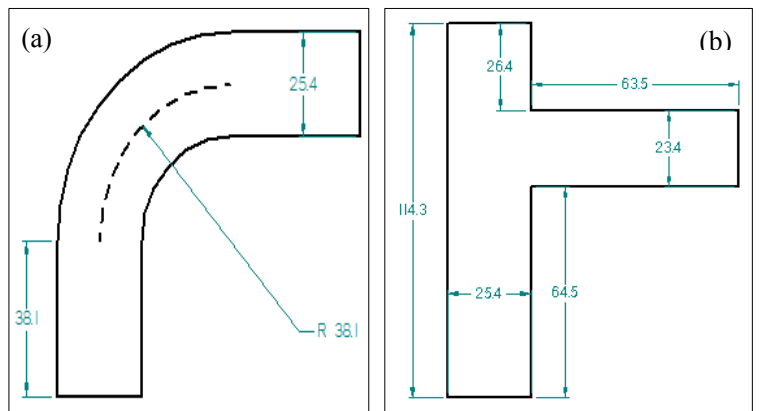

Fig. 1 Schematic figure of (a) elbow and (b) T-junction with geometry dimensions in $\mathbf{m m}$.

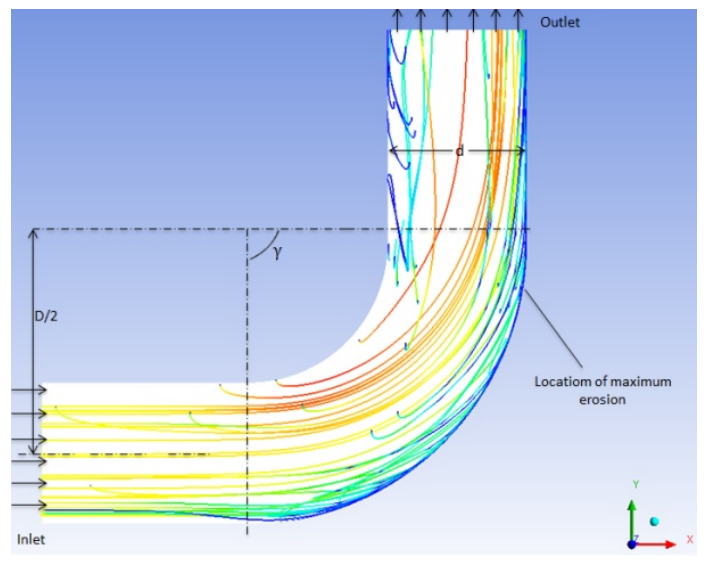

Fig. 2 Solid particles transport in a $90^{\circ}$ pipe bend.

hollow is nearer to the bend outlet in the case of liquid-solid flow. Particularly in danger are the bends with a ratio of curvature to pipe radius between 4 and 7 which the erosion rates become reasonably greater [6]. The angle of curvature $\gamma$, as defined in Fig. 2 is another important factor for bend erosion. With increase in angle of curvature $\gamma$, the wear increases steadily and reaches the highest value at $90^{\circ}$. In the locations where application of a long radius elbow due to the space considerations is limited, T-shaped junctions are preferred to use rather than standard elbows.

Elbows and $\mathrm{T}$-junctions have been studied experimentally and numerically by different researchers [7-11]. CFD as a modern tool is also applied for erosion predictions in elbows and T-junctions [12-15]. However, the experimental study and simulation of these parts facing the liquid-solid flows are very limited in literature. Chen et al. [16] investigated numerically and experimentally the comparison of erosion rates between $\mathrm{T}$-junctions and 
elbows for dilute gas-solid flow. Bourgoyne [8] did the same comparison study but for gas-solid flow with high volumetric solid concentration. Bourgoyne results showed a big difference from the observations of Chen et al. [16] due to the high solid particle concentration.

In the present study, a CFD tool coupled with an erosion model is applied to investigate and compare the relative erosion rates (hydroabrasion) of a $\mathrm{T}$-junction and elbow for a water-sand mixture flow and comparing with the air-sand mixture flow. The applied erosion model for the current simulations is chosen by numerically calculate the erosion rate of the material under defined conditions with more than four various erosion models from literature. Afterwards, an erosion model which is in better agreement with our wear depth experimental measurements and also the experimental results of Wang et al. [17] was applied for further calculations in the present study.

Achievement of two main goals is followed in this article. First, determination of the averaged amount of wear over the surfaces of both geometries and the second goal is to determine the location and value of maximum wear occurred, which would be an important key to predict the applicable life time of each geometry. The erosion rates of elbow and $\mathrm{T}$-junction for $\mathrm{a}$ specified target material (aluminum alloy 3.1645.51-Al $\mathrm{Cu} \mathrm{Mg} \mathrm{PbF38)} \mathrm{and} \mathrm{eroding} \mathrm{particle} \mathrm{material} \mathrm{(sand}$ particles) are predicted upon important influencing parameters such as flow velocity, sand concentration, particle size and particle shape. The aluminum 3.1645 is one of the aluminum alloys which are widely used in laboratory facilities constructions and thereby the evaluation of its erosion behavior is of a great importance.

The erosion process in these geometries are governed by three major mechanisms namely particle inertia force, drag force of the fluid and force of the secondary flows. For fluids like water which have a higher viscosity and higher density compared to air, particles are more controlled through the forces exerted by the surrounding fluid so that the drag force plays the major role, whereas for air, particles inertia is the dominant mechanism. In calculation of erosion rates, the difficulty arises in predicting the proper values of particle velocity and particle impact angle, whose values are dependent of fluid viscosity and density, particle diameter and density, apparatus geometry and its effects on flow shape. Moreover, the amount of solid particles hitting the target surface is influenced by the solid concentration and flow conditions and thereby it may not be identical with the total amount of solid particles in the flow [9]. Consideration of the mentioned factors is performed by using CFD analysis and particle tracking method.

\section{Geometry and Mesh Generation}

Three dimensional geometry and mesh of an elbow and T-junction with the inlet and outlet are shown in Figs. 3 and 4, respectively. The grid refinement is performed to find a stable numerical grid with an acceptable computational effort and as high as possible accurate simulation results. For this purpose, first of all, the geometry is meshed relatively fine using the O-grid technique for the circular cross sections of the geometry as depicted in Figs. 5 and 6, representing the mesh before and after the O-grid refinement, respectively. The mesh has been further optimized and refined in three steps. To maintain the relative grid elements length ratios and smooth transitions between the boundaries of the blocks, the number of nodes of each edge is increased 1.2 times in each refinement step, presented in Table 1 with the maximum mesh length ratio for each step. The $\mathrm{y}^{+}$near wall theory is also considered to reach a suitable element size in the vicinity of the walls. The maximum erosion rate $E_{\max }$ serves as a criterion for the mesh refinement control. This is presented together with its percentage deviation compared to each previous grid in Table 2.

According to Chen et al. [13], a deviation $(\delta)$ of the maximum erosion value of less than $20 \%$ for erosion calculations is sufficient. For this work in order to achieve a higher accuracy, a deviation of about $15 \%$ as 


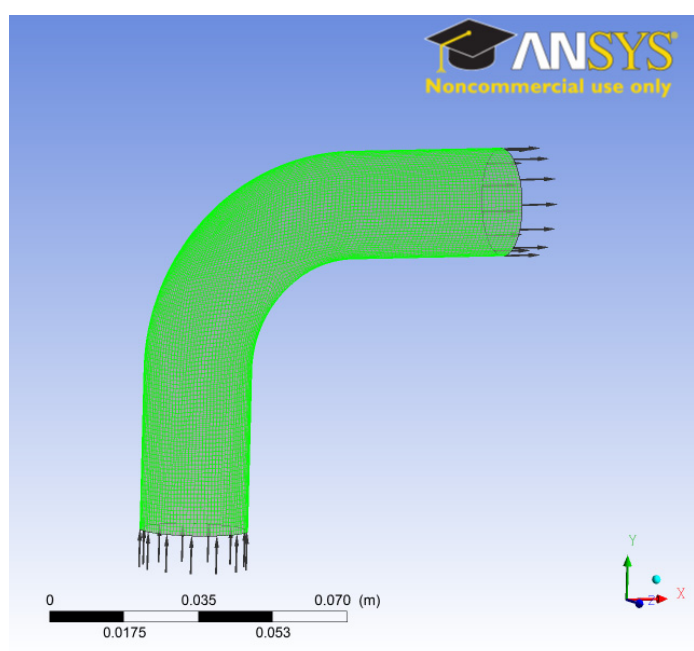

Fig. 3 3-D geometry and mesh of an elbow.

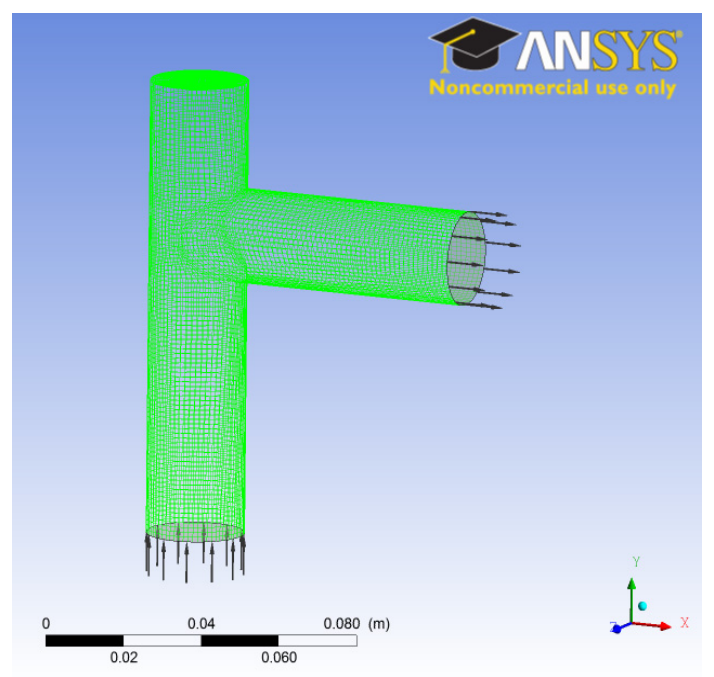

Fig. 4 3-D geometry and mesh of a T-junction.

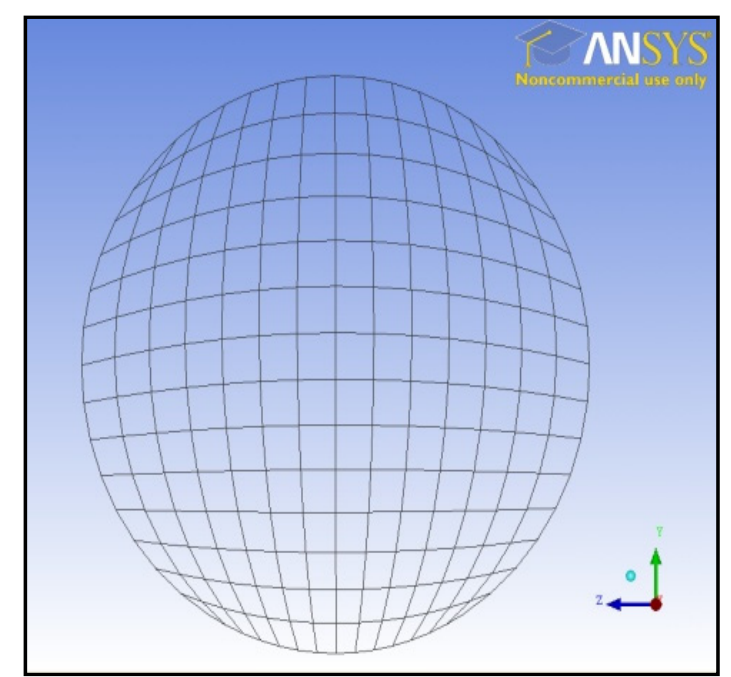

Fig. 5 Primary mesh of the pipe cross section.

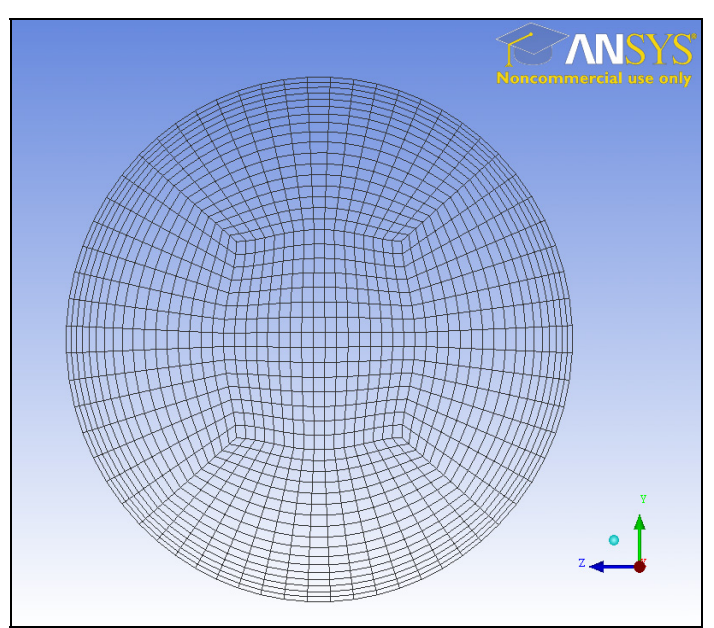

Fig. 6 Using O-grid mesh method to generate a fine mesh.

Table 1 Number of grid nodes of T-junction and elbow and the corresponding maximum edge length ratio $(\Delta)$.

\begin{tabular}{lllll}
\hline Refine step & $n_{\text {nodes,T-junction }}$ & $\Delta_{\text {T-junction }}$ & $n_{\text {nodes, elbow }}$ & $\Delta_{\text {elbow }}$ \\
\hline 1 & 152,568 & 6.25 & 147,032 & 7.14 \\
2 & 265,554 & 5.88 & 288,404 & 4.76 \\
3 & 514,218 & 4.34 & 482,752 & 4.00 \\
4 & 898,131 & 4.34 & 834,663 & 4.54 \\
\hline
\end{tabular}

Table 2 Maximum erosion and deviation $\delta$ for the various meshes of elbow and T-junction.

\begin{tabular}{lllll}
\hline $\begin{array}{l}\text { Refine } \\
\text { step }\end{array}$ & $\begin{array}{l}E_{\max , \text { elbow }} \\
\left(\mathrm{kg} / \mathrm{m}^{2} \mathrm{~s}\right)\end{array}$ & $\begin{array}{l}\delta_{\text {elbow }} \\
(\%)\end{array}$ & $\begin{array}{l}E_{\max , \text { T-junction }} \\
\left(\mathrm{kg} / \mathrm{m}^{2} \mathrm{~s}\right)\end{array}$ & $\begin{array}{l}\delta_{\mathrm{T}-\text { junction }} \\
(\%)\end{array}$ \\
\hline 1 & $3.23 \times 10^{-7}$ & - & $2.10 \times 10^{-7}$ & - \\
2 & $3.94 \times 10^{-7}$ & 18.12 & $3.76 \times 10^{-7}$ & 44.09 \\
3 & $4.87 \times 10^{-7}$ & 19.11 & $4.42 \times 10^{-7}$ & 15.00 \\
4 & $4.13 \times 10^{-7}$ & 15.17 & $4.60 \times 10^{-7}$ & 3.81 \\
\hline
\end{tabular}

authoritative is considered. Accordingly, as it is presented in Tables 1 and 2, the final mesh for the elbow part is selected as the third refinement step and for the T-junction as the second refinement step.

\section{Multiphase Modeling Approach}

A multiphase flow containing solid particles may be modeled using either the particle transport model namely Eulerian-Lagrangian approach or the Eulerian-Eulerian multiphase approach. In Eulerian-Eulerian multiphase, a momentum equation needs to be solved for each representative size which becomes very costly. The Eulerian-Lagrangian approach is applied in the present study since it is more flexible when there are multiple particle classes present 
in the fluid flow. This method provides more detailed information on behavior and residence time of individual particles [18]. The typical sand particles in pipelines are in the diameter range of $0.1 \mathrm{~mm}$ to 0.8 $\mathrm{mm}$ as it is depicted in Fig. 7 from experimental measurement by a HORIBA particle size analyzer (Retsch Technology, LA950 model) at our laboratory. Pepple [19] applied the phase Doppler method for dilute, turbulent liquid-solid flow in a vertical pipe and demonstrated that in general, the particles in the range of $0.5 \mathrm{~mm}$ damp the fluid turbulence while the particles in the range of $1.0 \mathrm{~mm}$ and $1.5 \mathrm{~mm}$ are either neutral or enhance the turbulence.

\subsection{Governing Equations of Particle Phase Using the} Lagrangian Approach

This approach calculates the trajectory of each individual discrete particle by integrating Newton's second law written in a Lagrangian reference frame (Chiesa et al. [20]). Influencing forces such as the drag and gravitational forces can be incorporated into the equation of motion. The equation can thus be written as:

$$
\frac{d u_{p}}{d t}=F_{D}\left(u_{f}-u_{p}\right)+\frac{g\left(\rho_{p}-\rho_{f}\right)}{\rho_{p}}
$$

where, $u_{f}$ and $u_{p}$ are the fluid and particle velocity, respectively. $\rho_{f}$ and $\rho_{p}$ are the fluid and particle density, respectively. $F_{D}\left(u_{f}-u_{p}\right)$ is the drag force per unit particle mass and $F_{D}$ is given by Eq. (2):

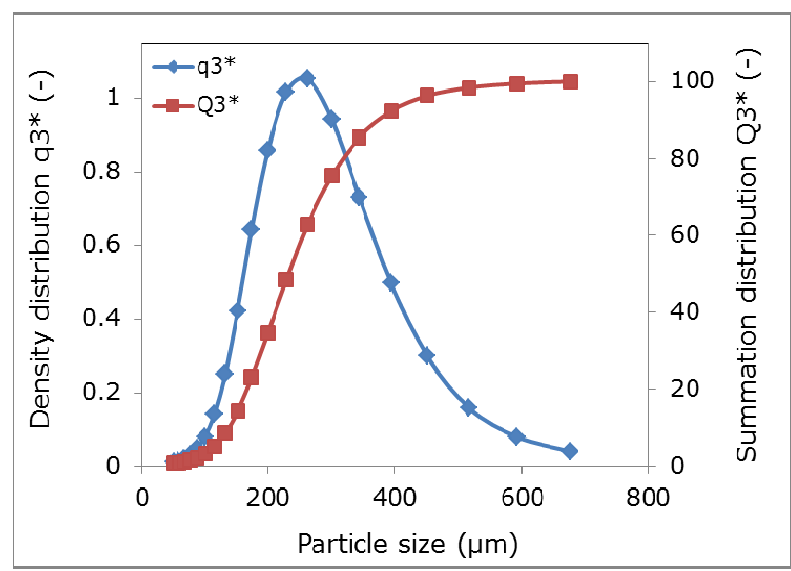

Fig. 7 Measured cumulative and summation size distribution of sand particles.

$$
F_{D}=\frac{18 \mu_{f}}{\rho_{p} d_{p}^{2}} \frac{C_{D} \operatorname{Re}_{p}}{24}
$$

The relative Reynolds number $R e_{p}$ is calculated as:

$$
R e_{p}=\frac{\rho_{p} d_{p}\left|u_{p}-u_{f}\right|}{\mu_{f}}
$$

\subsection{Influence of Particles on the Carrier Flow}

A converged solution of the coupled two-phase flow system is achieved by successive solution of the Eulerian and Lagrangian terms, respectively. First of all, the fluid flow is simulated without consideration of particle phase source terms until a converged solution is obtained. Afterwards, a large number of particles in the range of a hundred thousand are tracked through the flow field. In the initial Lagrangian calculation, inter-particle collisions are not taken into account. This is due to the fact that the required particle phase properties are not yet available. In this way, for each $\mathrm{CV}$ (control volume), the size and velocity correlations for the mean velocities and rms values, the particle concentration and particle size distribution are sampled while a computational particle crosses from this $\mathrm{CV}$ location. These properties are updated in each Lagrangian iteration to allow the correct calculation of inter-particle collisions. From the second Eulerian calculation, the source terms of the dispersed phase are introduced using an under relaxation procedure [21]. For the current simulations around 15 coupling iterations $\mathrm{t}$ with an under relaxation factor of around 0.4 were necessary to reach he full convergence. It is worth to mention that for higher particle concentrations, a stronger under relaxation factor was required which results an increase in the number of Euler-Lagrange iterations.

\subsection{Stokes Number}

The degree to which the solid particle motion is controlled and tied to the fluid motion can be evaluated by using the Stokes number which is defined as the ratio of the particle response time due to the viscous drag to a characteristic turbulent eddy time in the 
carrier fluid [22]. It is mathematically expressed as:

$S_{t}=($ solid response $t /$ fluid response $t)$

$$
=\frac{\rho_{p} d_{p}^{2} v_{s}}{18 \mu_{f} L_{s}}
$$

where, $v_{s}$ and $L_{s}$ are the characteristic velocity and length scales in the flow, respectively. $d_{p}$ is the particle diameter and $\mu_{f}$ is the dynamic viscosity of the carrier fluid. For values of Stokes number less than 0.25 , the effect of particle-wall interactions on the particle flow is almost negligible while the solid particles are tightly coupled to the fluid through viscous drag force. On the other hand, for large values of Stokes number bigger than 2.0, such as for low density gas-solid particles mixtures, the particulate flow is highly inertial and would be dominated by particle-wall interactions in a confined geometry [23].

\section{Computational Modeling}

The commercial computational fluid dynamics code ANSYS-CFX (14.5) is applied to calculate the flow velocity field, solid particles trajectory and resulting erosion rate of the pipe walls of the elbow and T-junction. CFX code is a finite volume algorithm based on a structured mesh that accepts a body fitted coordinate system and provides a multi block facility [17]. The steady state incompressible flow field was solved using 3-D structured mesh. The Menter Baseline two-equation turbulence model (BSL) is applied to represent the turbulent properties of the flow since it is better suited for the near wall modeling effects. The establishment of the turbulence model is realized by solving the Reynolds averaged Navier Stokes equations under suitable boundary and initial conditions.

\subsection{Boundary Conditions}

There are three regions surrounding the computational domain: inlet, walls and the outlet boundary. Velocity and volume fraction of both liquid and solid phases are introduced at the inlet section of the pipe geometry. For more accuracy, a fully developed velocity profile defined by Eq. (5) is set at the inlet:

$$
U=v_{\max }\left(1-\frac{r}{R_{\max }}\right)^{\frac{1}{n}}
$$

where, $v_{\max }$ is the pipe centerline velocity, $R_{\max }$ is the pipe radius and $r$ is the distance from the pipe centerline. $n$ is defined in regard to Reynolds number from $n=6$ for Reynolds number of around 4,000 to $n=$ 7 for a Reynolds number of around 110,000.

The solid concentration is defined as $\alpha_{s}=C_{p}$ and fluid concentration as:

$$
\alpha_{f}=1-C_{p}
$$

where, $C_{p}$ is the efflux concentration in the slurry pipeline [24] and can be computed using the following equation:

$$
C_{p}=\frac{1}{A} \int_{A} \bar{\alpha}_{s} d A \cong \frac{1}{A} \int_{A} \alpha_{s} d A
$$

For the pipe wall, no slip boundary condition with wall roughness of $1.5 \mu \mathrm{m}$ according to the material properties of aluminum given in Ref. [25] is used. The parallel and tangential restitution coefficients of sand particles in contact to the hard metals and in the velocity range of $5-20 \mathrm{~m} / \mathrm{s}$ are selected from the work of Gorham [26] and assumed to be 0.96 for both coefficients. Constant atmospheric pressure is set as the static pressure for the outlet sections. To study the effects of sand concentration, fluid velocity, solid particle size and particle shape on flow behavior and erosion rate of both geometries, three variables are kept constant in every simulation while the forth variable is varied.

\subsection{Application of an Erosion Model}

The selection of an appropriate erosion model which better fits to the experimental results was performed by calculating the erosion (material weight loss) of a square shaped $44 \mathrm{~W}$ carbon steel specimen in continuous contact to a vertical water-sand jet for some various operating conditions with four different erosion 
models from Refs. [13, 27-29]. The results are then compared with the experimental erosion results of Wang et al. [17] which applied a water-sand jet experimental setup to investigate the effects of influencing parameters on the erosion rate of the $44 \mathrm{~W}$ carbon steel specimens. The schematic figure of the particle-water jet discharging from the nozzle impacting a sample plate is depicted in Fig. 8. The experimental erosion tester is the same setup as the one applied for our experiments measuring the wear depth (Fig. 9a) of the surface of aluminum alloy specimen, in order to compare and validate with CFD results shown in Fig. 9b. As it is observed in Figs. 9a and 9b, due to the ductility of aluminum alloy, the erosion or penetration rate of the surface where the jet hits the surface with an angle of $90^{\circ}$ is very low near to zero value, the erosion increases reaching the maximum values around the contact angles of $60^{\circ}$ to $40^{\circ}$ and decreases again towards zero when the contact angle decreased further towards $0^{\circ}$. The contact angle in here is defined as the angle between the slurry jet and the eroded surface. According to Fig. 9b, the CFD results applying the Grant-Tabakoff erosion model fits quite well with our wear depth experimental tests on an aluminum alloy specimen. Moreover, the material loss versus solid particles concentration was calculated with application of erosion models of Finnie, McLaury, Huang and Grant-Tabakoff. As it is depicted in Fig. 10, the erosion results from Grant-Tabakoff model fits very well with the experimental results of Wang et al. [17] and thereby was selected for the current study simulations of the erosion rate for elbow and T-junction parts. The highest deviation of erosion according to Fig. 10, occurs when the Finnie erosion model is applied. This is due to the fact that in Finnie model, the surface and particles materials properties and also their effects on the erosion are not fully taken into consideration.

Numerical prediction of metallic surface erosion is usually based on the empirical correlation of the given particle-surface material properties associated with the particle impact conditions. Tabakoff et al. [27, 30] has experimentally indicated that the erosion of a specimen is mostly dependent on the particle impingement angle and its impact velocity. The uniqueness of this model

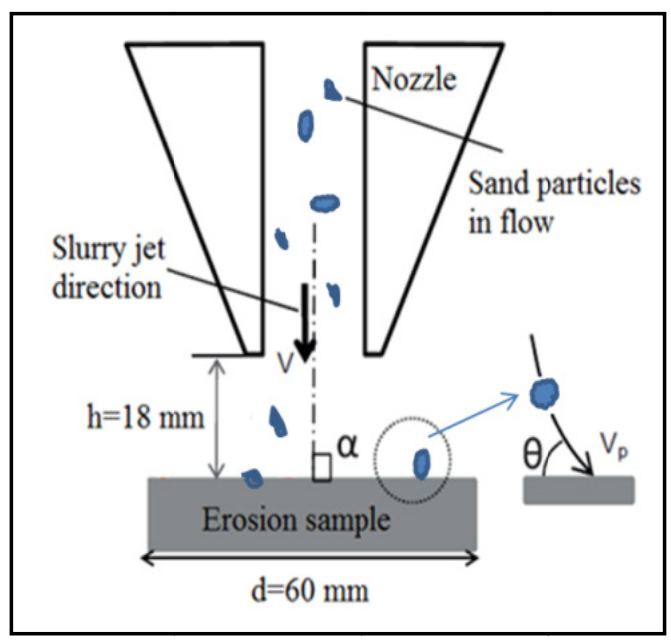

Fig. 8 Slurry jet experimental tester.
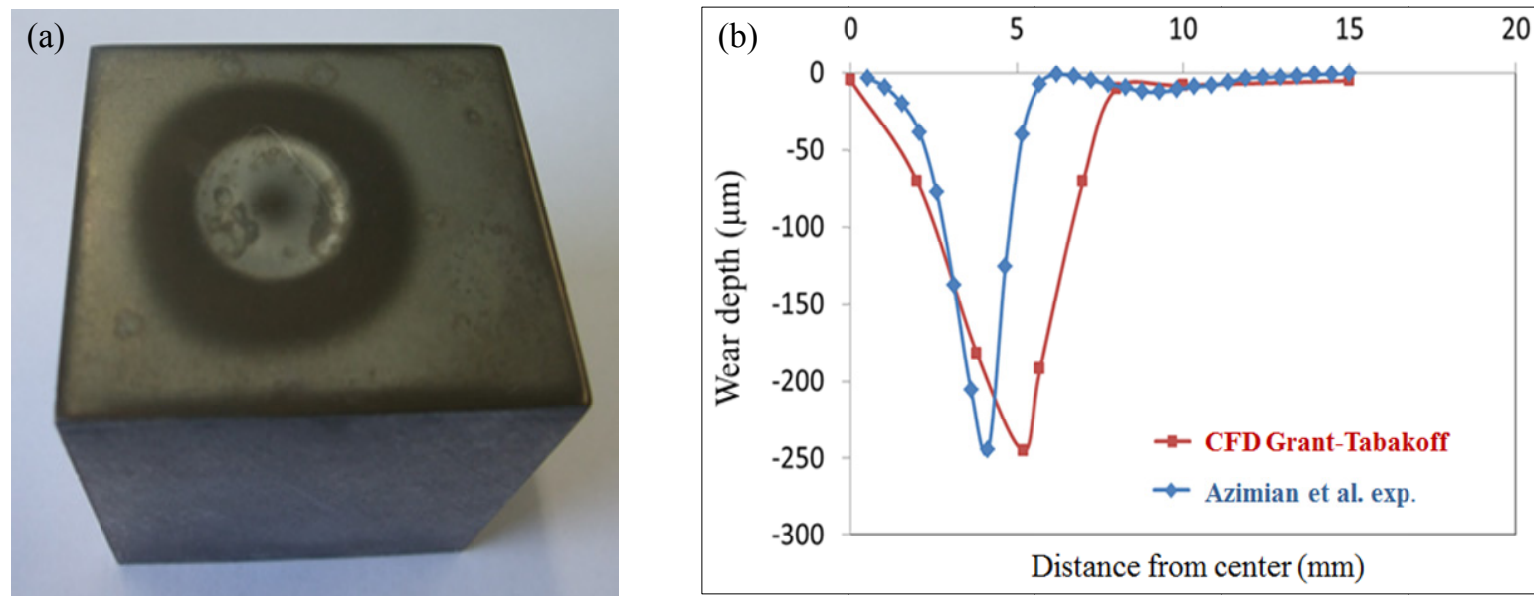

Fig. 9 (a) Aluminum alloy sample after $10 \mathrm{~h}$ erosion test; (b) Exp./CFD comparison of wear depth. 


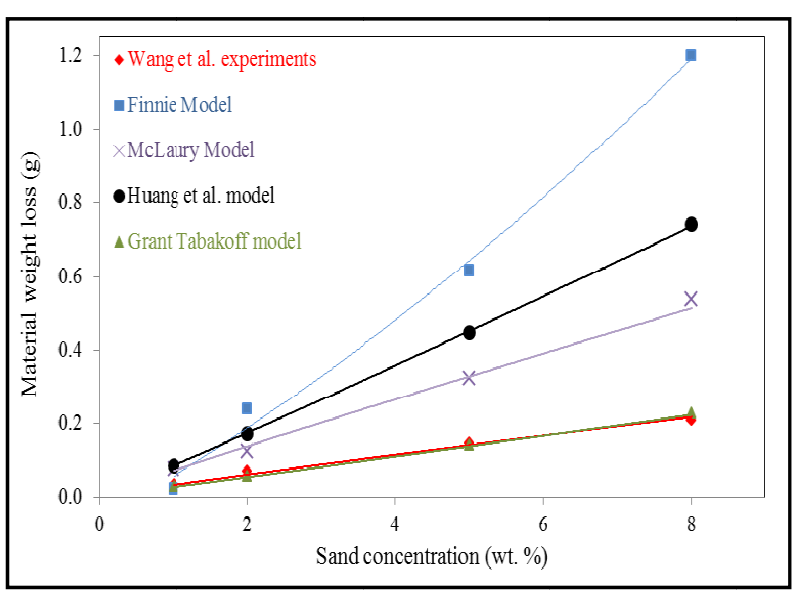

Fig. 10 Erosion predictions with various erosion models and comparison with exp. results.

when compared to other erosion models of its kind is that it incorporates the particle restitution coefficient, and in particular the tangential restitution coefficient $R_{T}$ as one of the parameters affecting the erosion rate.

The following equation was developed by Grant and Tabakoff [27] to predict the erosion of ductile metals and alloys and is defined as the ratio of the eroded mass of target material to the mass of impinging solid particles.

$$
E=k_{1} f\left(\beta_{1}\right)\left(V_{1 T}^{2}-V_{2 T}^{2}\right)+f\left(V_{1 N}\right)
$$

where, $k_{1}$ is the material constant, $f\left(\beta_{1}\right)$ is the empirical function of particle impact angle, $V_{I T}$ and $V_{2 T}$ are the tangential component of incoming particle velocity and of rebounding particle velocity, respectively. $f\left(V_{1 N}\right)$ is the component of erosion due to the normal component of velocity. The tangential restitution ratio is defined as follows:

$$
R_{T}=\frac{V_{2 T}}{V_{1 T}}=1-k_{4} V_{1} \sin \beta_{1}
$$

By inserting $V_{1 T}=V_{1} \cos \beta_{1}$, the erosion Eq. (10) can be derived:

$$
E=k_{1} f\left(\beta_{1}\right) V_{1}^{2} \cos ^{2} \beta_{1}\left(1-R_{T}^{2}\right)+f\left(V_{1 N}\right)
$$

The effect of the particle approach angle is lumped into $f\left(\beta_{1}\right)$, and a strict empirical approach is used to predict its behavior. The result of this analysis yields the following expression:

$$
f\left(\beta_{1}\right)=\left[1+k_{2} k_{12} \sin \left(\frac{\pi \beta_{1}}{2 \beta_{0}}\right)\right]^{2}
$$

where, $\beta_{0}$ is the angle of attack where the maximum erosion occurs, $k_{12}$ is a material constant and:

$$
k_{2}: \begin{cases}1 & \beta_{1} \leq 2 \beta_{0} \\ 0 & \beta_{1}>2 \beta_{0}\end{cases}
$$

The component of erosion resulting from normally impacting particles is expressed as:

$$
f\left(V_{1 N}\right)=k_{3}\left(V_{1} \sin \beta_{1}\right)^{4}
$$

The $k_{12}$ constant, the reference velocity values and the angle of maximum erosion required for the Grant-Tabakoff erosion model for aluminum alloy surface and also for $44 \mathrm{~W}$ carbon steel surface, both eroded by sand particles are given in Table 3 .

Overall erosion rate of the wall due to the solid particles interactions with the wall is finally computed from the following equation:

$$
\dot{E}=\dot{N} \cdot m_{p} \cdot E
$$

where, $\quad \dot{N}$ is the number rate of solid particles and $m_{p}$ is the particle mean mass.

\subsection{Simulation Conditions}

The density of dry sand is given in Table 4, however, the atomic packing factor for precise determination of the bulk sand density must be taken into account. The APF (atomic packing factor) or packing fraction is the fraction of volume in a bulk structure that is occupied by atoms. For one-component materials, the $A P F$ is determined mathematically by the following equation:

$$
A P F=\frac{N_{\text {atoms }} \cdot V_{\text {atom }}}{V_{\text {unitcell }}}
$$

By taking the $A P F \approx 0.7$ from literature for the bulk sand, the density of saturated wet sand will be assumed as $2,300 \mathrm{~kg} / \mathrm{m}^{3}$ for the CFD simulations. The CFD simulations are performed to predict how the erosion rate of elbows and T-junctions for a specified target material is changing with various influencing parameters. The four important parameters investigated here are the feed flow velocity, solid particle concentration, solid particle size and solid particle shape. The simulation parameter conditions are presented in Table 5. 
Table 3 Coefficients for aluminum alloy and $44 \mathrm{~W}$ carbon steel surfaces eroded by sand particles.

\begin{tabular}{lll}
\hline Parameter & $\begin{array}{l}\text { Aluminum } \\
\text { alloy-sand } \\
\text { particles }\end{array}$ & $\begin{array}{l}44 \mathrm{~W} \text { carbon } \\
\text { steel-sand } \\
\text { particles }\end{array}$ \\
\hline$k_{12}$ & 0.585 & 0.266799 \\
Ref. velocity $u_{1}$ & 521.9957 & 437.4786 \\
Ref. velocity $u_{2}$ & 638.943 & $1,161.73$ \\
Ref. velocity $u_{3}$ & 625 & 625 \\
Angle of max. erosion & $25^{\circ}$ & $30^{\circ}$ \\
\hline
\end{tabular}

Table 4 Physical properties of sand and water.

\begin{tabular}{llll}
\hline Material & $\begin{array}{l}M \\
(\mathrm{~g} / \mathrm{mol})\end{array}$ & $\begin{array}{l}\rho \\
\left(\mathrm{kg} / \mathrm{m}^{3}\right)\end{array}$ & $\begin{array}{l}c \\
(\mathrm{~J} / \mathrm{kgK})\end{array}$ \\
\hline Water & 18.02 & 997.0 & $4,181.7$ \\
Sand (dry) & 60.10 & 1620.0 & 800.0 \\
\hline
\end{tabular}

Table 5 Erosion simulation conditions of elbow and T-junction.

\begin{tabular}{llllll}
\hline$v$ & $\begin{array}{l}C_{p} \\
(\mathrm{~m} / \mathrm{s})\end{array}$ & $\begin{array}{l}d_{p} \\
(\text { Vol.- } \%)\end{array}$ & $\begin{array}{l}f_{s} \\
(\mathrm{~mm})\end{array}$ & $\begin{array}{c}\dot{m}_{w} \\
(\mathrm{~kg} / \mathrm{s})\end{array}$ & $\begin{array}{l}\dot{m}_{p} \\
(\mathrm{~kg} / \mathrm{s})\end{array}$ \\
\hline 5 & 3 & 0.15 & 1 & 2.53 & 0.18 \\
10 & 3 & 0.15 & 1 & 5.05 & 0.36 \\
15 & 3 & 0.15 & 1 & 7.58 & 0.54 \\
20 & 3 & 0.15 & 1 & 10.10 & 0.72 \\
5 & 3 & 0.15 & 1 & 2.53 & 0.18 \\
5 & 5 & 0.15 & 1 & 2.53 & 0.31 \\
5 & 8 & 0.15 & 1 & 2.53 & 0.51 \\
5 & 10 & 0.15 & 1 & 2.53 & 0.64 \\
5 & 3 & 0.05 & 1 & 2.53 & 0.18 \\
5 & 3 & 0.15 & 1 & 2.53 & 0.18 \\
5 & 3 & 0.25 & 1 & 2.53 & 0.18 \\
5 & 3 & 0.35 & 1 & 2.53 & 0.18 \\
5 & 3 & 0.45 & 1 & 2.53 & 0.18 \\
5 & 3 & 0.25 & 0.2 & 2.53 & 0.18 \\
5 & 3 & 0.25 & 0.4 & 2.53 & 0.18 \\
5 & 3 & 0.25 & 0.6 & 2.53 & 0.18 \\
5 & 3 & 0.25 & 0.8 & 2.53 & 0.18 \\
5 & 3 & 0.25 & 1 & 2.53 & 0.18 \\
\hline
\end{tabular}

\section{CFD Simulation and Particle Tracking}

It is observed that for water-sand flow in the elbow, due to the big drag forces exerted on the particles by water flow, the particles follow closely the fluid streamlines (Fig. 11). This causes a shift in location of maximum erosion nearer to exit part of the elbow compared to the erosion location caused by air-sand mixture flow. In T-junctions, more particles deviate from the flow streamlines (Fig. 12) and contact the

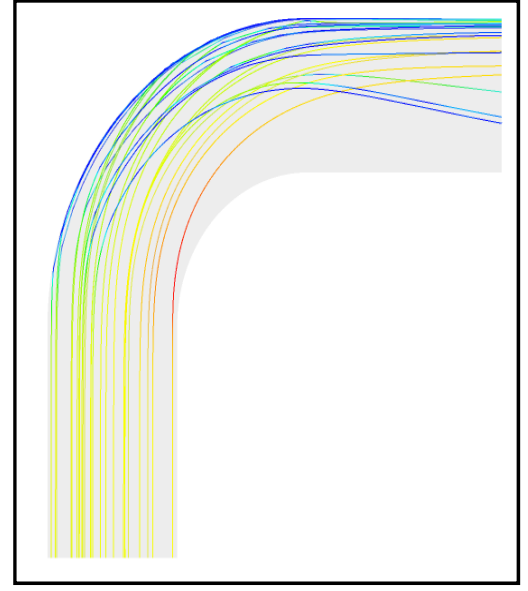

Fig. 11 Particle tracking in an elbow part.

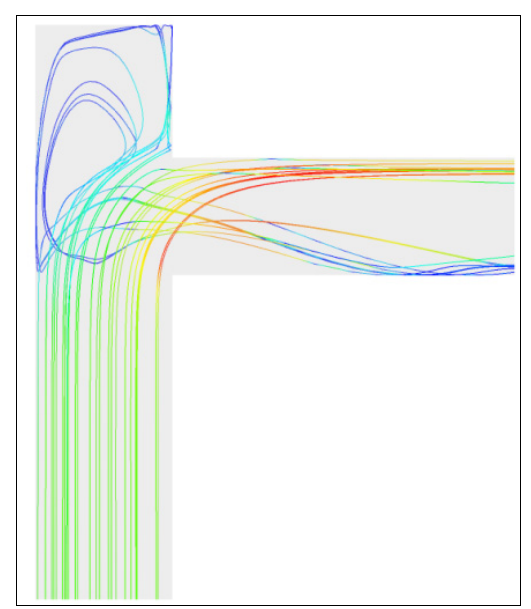

Fig. 12 Particle tracking in a $\mathrm{T}$-junction part.

joint corner of the $\mathrm{T}$-junction resulting a greater erosion rate. Simulations with various influencing parameters predict that the erosion rates of $\mathrm{T}$-junction are relatively greater than elbows for all the predicted conditions in the current study.

As demonstrated by Chen et al. [16], the erosion rates of elbows and T-junctions by air-sand flow are comparable with each other since the effect of drag force is smaller and thereby for some specific operating conditions, application of T-junctions are more economical than the elbows. Our CFD simulation results of the elbow and T-junction for the air-sand particles flow is compared to the experimental results of Chen et al. [16] and depicted in Fig. 13. The CFD results match qualitatively well with experimental data. However, the simulation results are averaged over the whole geometry of the elbow and T-junction but the 


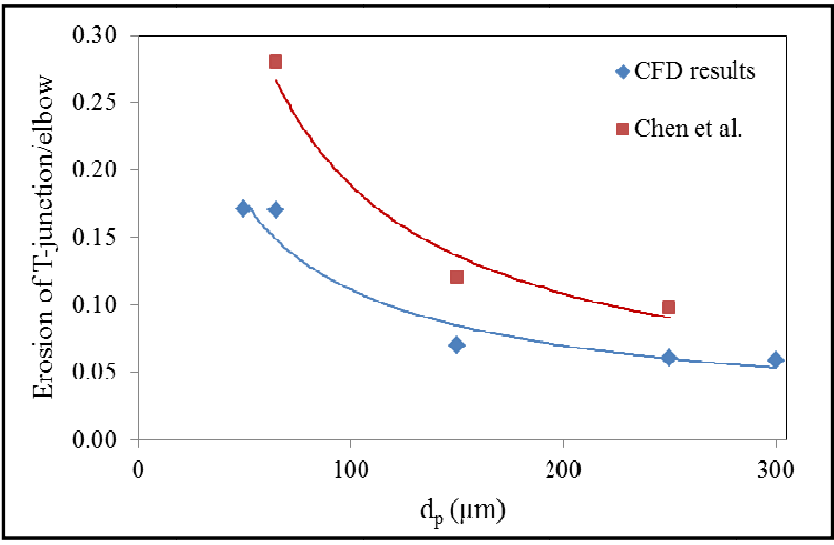

Fig. 13 CFD/Chen et al. exp. comparison for air-sand flow.

experimental results belong to the side and corner regions of the $\mathrm{T}$-junction. The simulation results for the relative erosion of T-junction to elbow would shift a bit below the experimental results. This qualitative comparison however approves the fact that for air-solid flows in some operational conditions, the T-junctions compared to the elbows are more resistant to erosion. Chen et al. [16] demonstrated that for air (gas)-solid flow, maximum erosion in elbows occurs always at the projected area from the elbow inlet cross section and in $\mathrm{T}$-junctions occurs at the end region and upper corner of the T-part.

In the present study, it is proved that for liquid (water)-solid flow, the maximum erosion in T-junctions occurs on the side surfaces near the exit area and also near the welded positions mainly at upper corner of the junction area as shown in Fig. 14. The maximum erosion in elbows for water-sand flow as depicted in Fig. 15 occurs nearer to the exit area of the elbow in comparison with the location of maximum erosion for air-sand flow in the elbow. The erosion locations of an elbow when the flow in contra gravity direction flows (from bottom to top) as depicted in Fig. 15, is also compared to erosion locations of an elbow when the flow in gravity direction flows (from top to bottom) presented in Fig. 16. As it is observed from these two figures, the erosion locations of the latter like the former occurs from the beginning part to the end of the elbow, but the latter one has a higher erosion density and severity due to the gravitational force direction. This

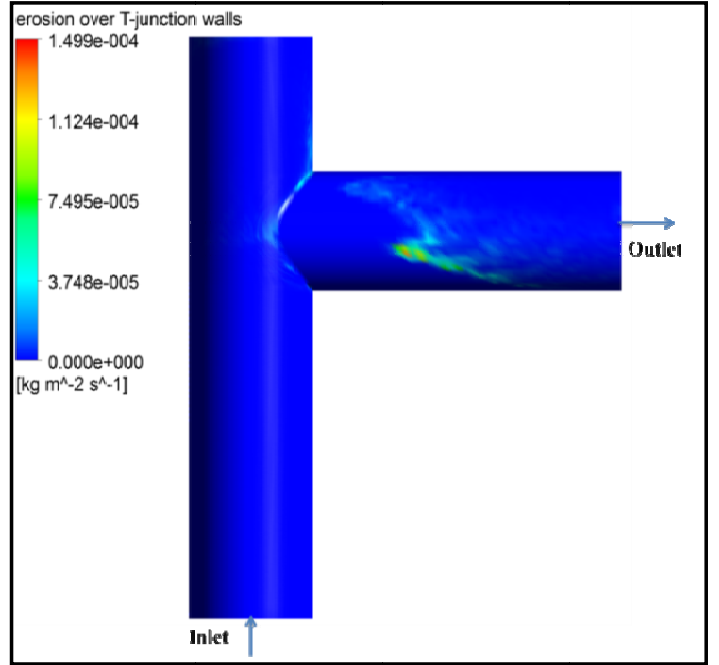

Fig. 14 Erosion rates at corner and side walls of a T-junction.

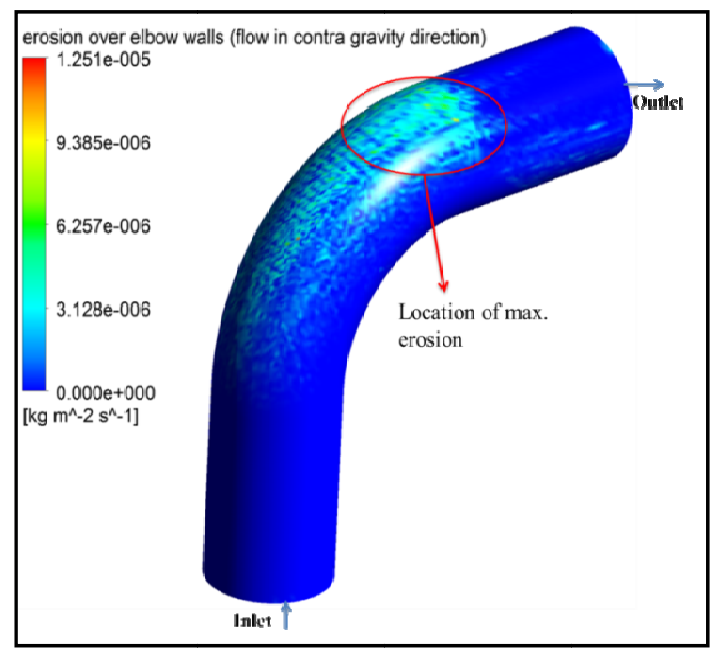

Fig. 15 Erosion locations at wall surface of an elbow (flow in contra gravity direction from bottom to top).

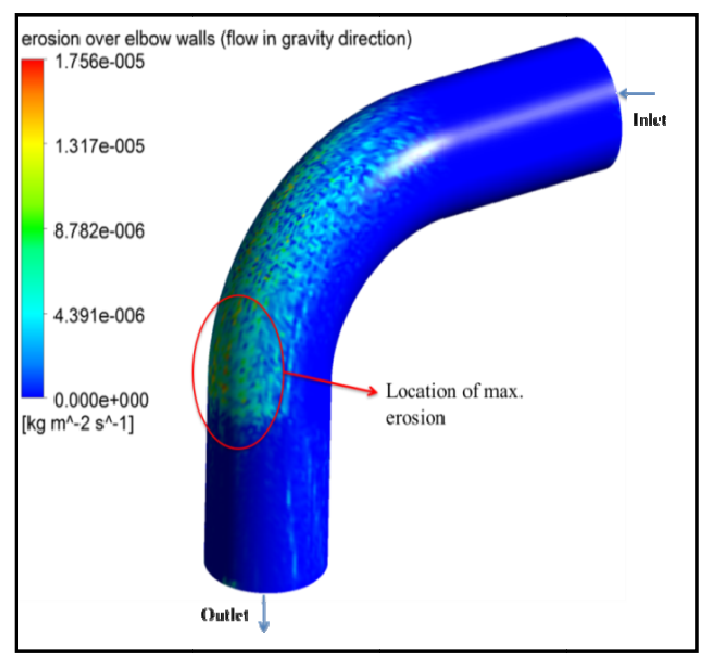

Fig. 16 Erosion locations on wall surface of an elbow (flow in the gravity direction from top to bottom). 
is due to the fact that the particles are tied more onto the walls of the elbow and thereby have more interactions with the walls.

Fig. 17 presents a quantitative comparison between the erosion rates of the elbow with upwards flow (in contra gravity direction) and the elbow with downwards flow (in gravity direction). As it is depicted in Fig. 17, the erosion rate of the elbow with downwards flow is with a factor of almost 2 higher than the erosion rate of the elbow with upwards flow for all the considered inlet flow velocities.

\section{Effects of Influencing Parameters}

The erosion model must contain all the important erosion parameters as separate variables and all excluded minor erosion parameters should be included in an erosion constant. The basic structure of the erosion model for a specified target material should include the four most important erosion parameters as presented in Eq. (16):

$$
E=k \cdot f_{1}(v) \cdot f_{2}\left(C_{p}\right) \cdot f_{3}\left(d_{p}\right) \cdot f_{4}\left(f_{s}\right)
$$

where, $k$ is the erosion constant, $f_{1}(v)$ is the flow velocity term, $f_{2}\left(C_{p}\right)$ is the solid particle concentration term, $f_{3}\left(d_{p}\right)$ is the solid particle size term, and $f_{4}\left(f_{s}\right)$ is the solid particle shape factor term.

\subsection{Flow Velocity Effects}

The effects of flow velocity on the average erosion rate and maximum erosion rate of elbow and T-junction are given in Figs. 18a and 18b, respectively.

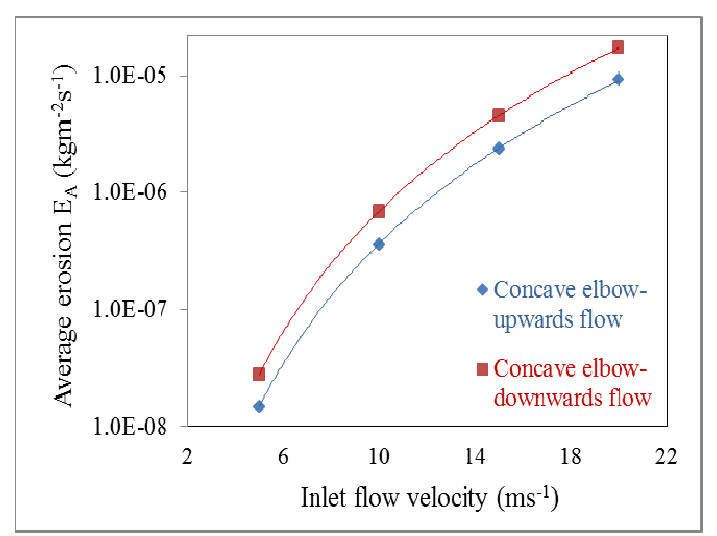

Fig. 17 Comparison of the erosion of elbow with upwards and downwards flow directions.
The nozzle discharge angle and the sand concentration were fixed $90^{\circ}$ and 3 vol.- $\%$, respectively. The stand-off distance between nozzle and surface of target was $18 \mathrm{~mm}$. Four different impingement velocities, 5 $\mathrm{m} / \mathrm{s}, 10 \mathrm{~m} / \mathrm{s}, 15 \mathrm{~m} / \mathrm{s}$ and $20 \mathrm{~m} / \mathrm{s}$, were used in the calculations. It can be observed from Figs. $18 \mathrm{a}$ and $18 \mathrm{~b}$, that the erosion rate can be expressed by a linear curve in the logarithmic scale. Therefore, the erosion rate can be described by a power law of the flow velocity as follows:

$$
E=k_{a} \cdot f_{1}(v)=k_{a} \cdot\left(\frac{v}{v_{r e f}}\right)^{a}
$$

where, $v_{\text {ref }}$ is the reference flow velocity and used to make impacting flow velocity term dimensionless form.

\subsection{Solid Particle Concentration Effects}

The effects of solid particle concentration on the average erosion rate and the maximum erosion rate of elbow and T-junction are given in Figs. 19a and 19b, respectively. In this case, only sand concentration was changed, whereas the other parameters were kept constant. Four different sand concentration of 3 vol.- $\%$, 5 vol.- $\%, 8$ vol.- $\%$ and 10 vol.- $\%$ were used in the inlet flow impacting an aluminum alloy specimen at conditions of impact velocity of $5 \mathrm{~m} / \mathrm{s}$ and discharge angle of $90^{\circ}$. As depicted in Figs. 19a and 19b, the erosion rate can be expressed by a logarithmic curve in the logarithmic scale as the following equation:

$$
E=k_{b} \cdot f_{2}\left(C_{p}\right)=k_{b} \cdot \ln \left(\frac{C_{p}}{C_{p, r e f}}\right)
$$

where, $C_{p, r e f}$ is the reference sand concentration and used to make the solid particle concentration term dimensionless form.

\subsection{Solid Particle Size Effects}

The effects of solid particle size on the average erosion rate and maximum erosion rate of elbow and T-junction are given in Figs. 20a and 20b, respectively. Five different sand particle stream sizes of 50, 150, 250, 350 and 450 micrometer were used while the impact velocity of $5 \mathrm{~m} / \mathrm{s}$, sand concentration of 3 vol.- $\%$ and 

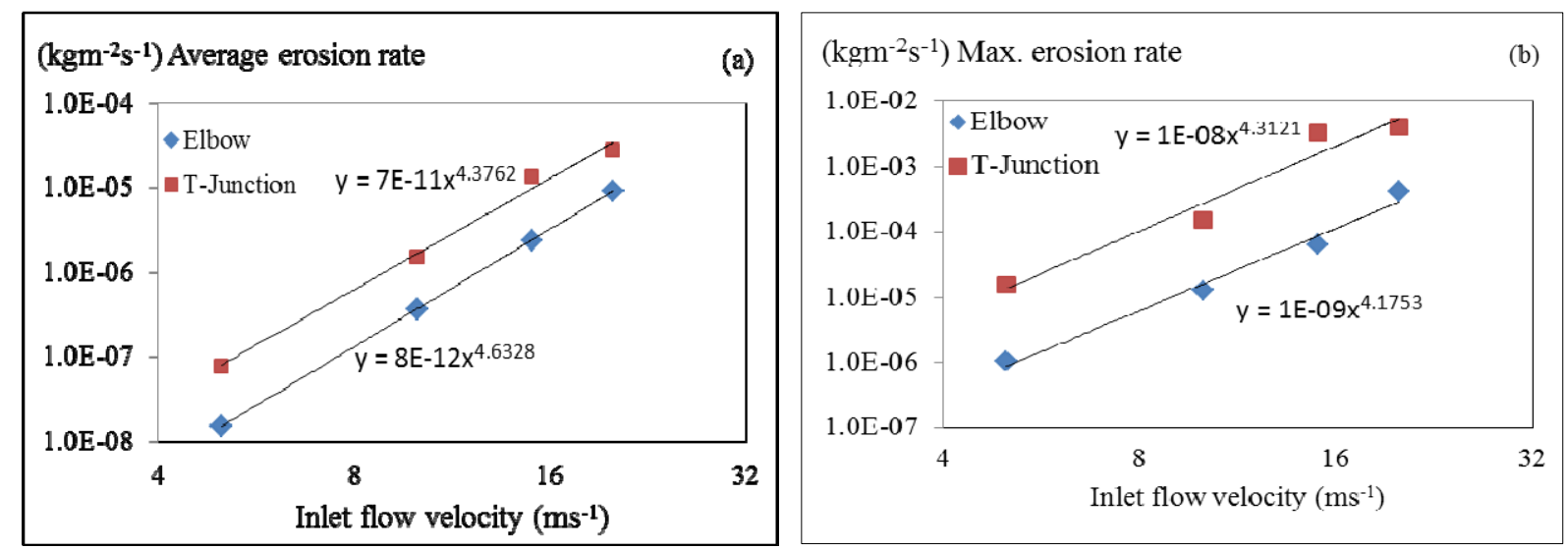

Fig. 18 (a) Avg. erosion rate and (b) Max. erosion rate of elbow \& T-junction as a function of inlet flow velocity.

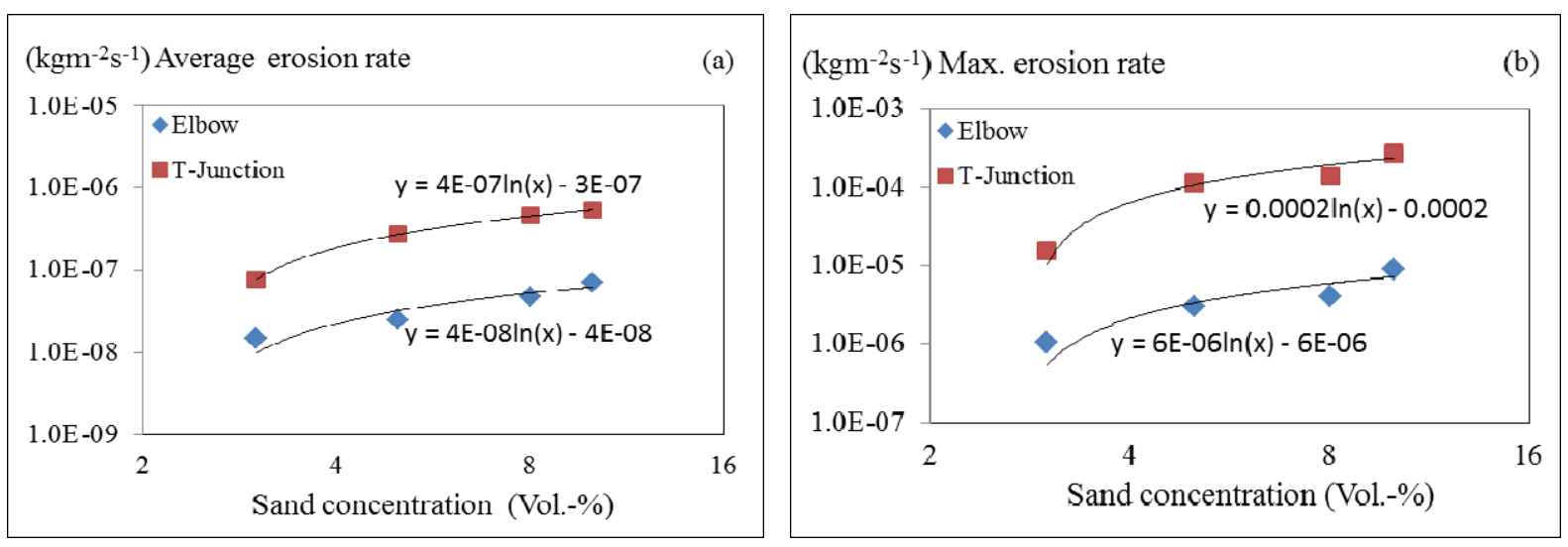

Fig. 19 (a) Avg. erosion rate and (b) Max. erosion rate of elbow and T-junction as a function of sand concentration.
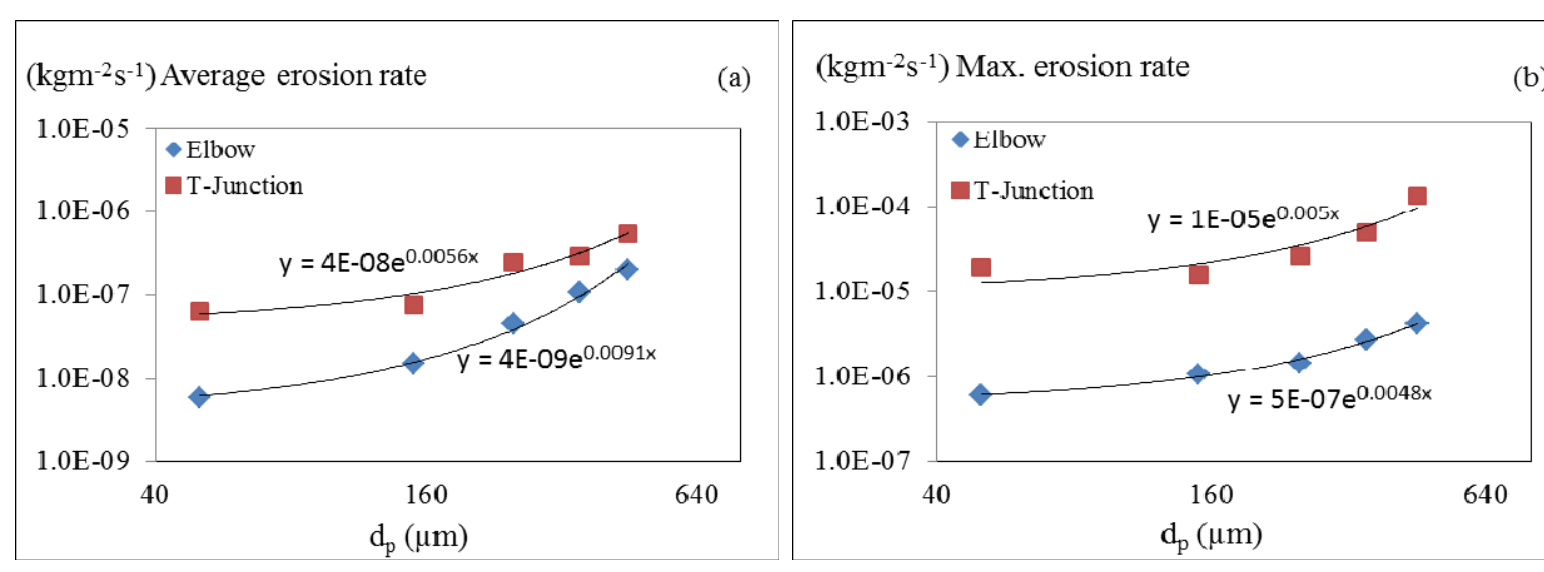

Fig. 20 (a) Avg. erosion rate and (b) Max. erosion rate of elbow and T-junction as a function of particle size.

shape factor of 1 were kept constant. It can be observed from Figs. 20a and 20b, that the erosion rate can be expressed by an exponential curve in the logarithmic scale as the following equation:

$$
E=k_{c} \cdot f_{3}\left(d_{p}\right)=k_{c} \cdot e^{\gamma\left(\frac{d_{p}}{d_{p, r e f}}\right)}
$$

where, $d_{p, r e f}$ is the reference sand particle size and used to make the solid particle size term dimensionless form and $\gamma$ is a constant to be determined.

\subsection{Solid Particle Shape Effects}

The effects of solid particle shape on the average erosion rate and maximum erosion rate of elbow and T-junction are given in Figs. 21a and 21b, respectively. 

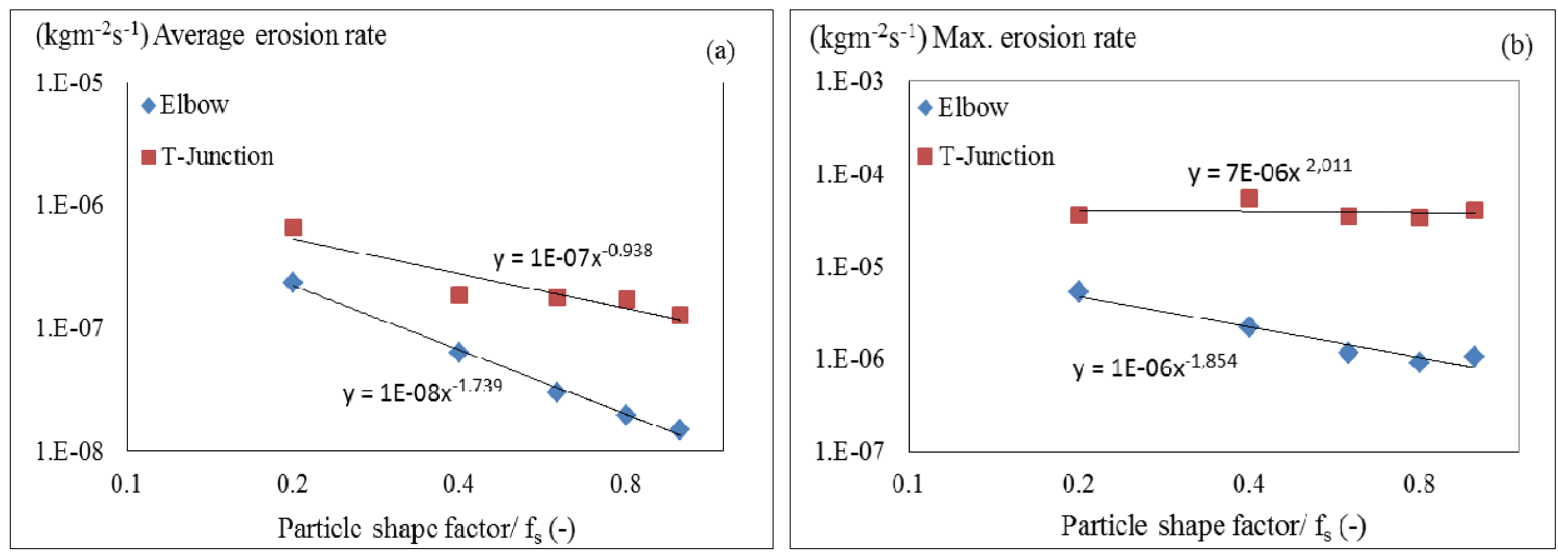

Fig. 21 (a) Avg. erosion rate and (b) Max. erosion rate of elbow and T-junction as a function of particle shape.

As it is depicted in these figures, the erosion rate can be expressed by a linear curve in the logarithmic scale as follows:

$$
E=k_{d} \cdot f_{4}\left(f_{s}\right)=k_{d} \cdot f_{s}^{\beta}
$$

where, $\beta$ is a constant to be determined, $f_{s}$ is the dimensionless average shape factor of the sand particles which needs no reference value to make it dimensionless. The shape factor of 0 represents a disc shaped particle and 1 a spherical shaped particle. Five different shape factors varying from 0.2 to 1 were examined by keeping the impact velocity as $5 \mathrm{~m} / \mathrm{s}$, the sand concentration as 3 vol.- $\%$ and sand stream particle size as 250 micrometer.

\section{Conclusions}

The average erosion rate and maximum erosion rate due to the liquid-solid mixture flow impacting the walls of an elbow and T-junction parts of a pipeline is calculated with CFD tool coupled with an erosion model. The wear depth and erosion of a square shaped specimen eroded by a vertical water-sand jet tester for some various influencing parameters were modeled and compared with our wear depth experiments and also the experimental erosion results of Wang et al. [17]. Accordingly, the modified Grant-Tabakoff erosion model is selected for the erosion predictions of T-junction and elbow parts since it fits better with the experimental results. The BSL turbulence model is applied to represent the turbulent properties of the flow since it is better suited for the near wall modeling effects. Comparison of the maximum erosion location in elbow with experimental results published in literature such as Blanchard [7] shows a qualitatively good agreement. The effects of important erosion influencing parameters such as feed flow velocity, sand concentration, particle size and particle shape on erosion rate of elbow and $\mathrm{T}$-junction parts are investigated in detail and presented. It is approved that for gas-solid flows, in some operational conditions the T-junctions are more wear resistant than elbows. Our CFD simulation results of the elbow and T-junction for the air-sand flow is compared to the experimental results of Chen et al. [16]. The results match qualitatively well together approving the fact that application of T-junction instead of elbow in such cases could be more economical. Moreover, it is shown in details that the erosion rate of $\mathrm{T}$-junction due to liquid-solid flow is relatively greater than elbow for all the simulated operating conditions. Thereby, the application of T-junction instead of elbow in the case of liquid-solid flows is not recommended. Due to the lack of experimental results for the liquid-solid flows in pipeline parts such as elbows and T-junctions, further experimental investigations applying an industrially slurry pump are in progress by the authors to validate the further CFD simulation results.

\section{Acknowledgment}

The authors would like to thank "Stiftung Rheinland-Pfalz für Innovation" for financial support. 


\section{References}

[1] M. Hutchings, The Erosion of Materials by Liquid Flow, Natl Assn of Corrosion, USA, 1986.

[2] K. Sommer, R. Heinz, J. Schöfer, Verschleiß metallischer Werkstoffe, 1. Auflage, 2010.

[3] M. Takaffoli, M. Papini, Finite element analysis of single impacts of angular particles on dilute targets, Wear 267 (2009) 144-151.

[4] E. Gödde, E. Kriegel, Werkstoffe für Rohre zum hydraulischen Transport von Feststoffen, Maschinenmarkt 88 (1982) 2074-2077.

[5] H. Gaessler, W. Prettin, Planungsgrundlagen für die hydraulische Kohlenförderung, Glückauf-Forschungshefte 36 (1975) 185-194.

[6] B. Brauer, E. Kriegel, Erosion of pipelines by hydraulic flow of solid materials, Steel and Iron 84 (1964) 1313-1322.

[7] D.J. Blanchard, Erosion of metal pipe by solid particles entrained in water, Master Thesis, MIT, Massachusetts, USA, 1981.

[8] A.T. Bourgoyne, Experimental study of erosion in diverter systems due to sand production, in: Proceedings of SPE/IADC-18716, Louisiana, Feb. 28-March 3, 1989.

[9] M.M. Salama, An alternative to API 14E erosional velocity limits for sand laden fluids, ASME J. Energy Res. Tech. 122 (2000) 71-77.

[10] B.S. McLaury, S.A. Shirazi, Is API RP 14E reliable for predicting an erosional production velocity when sand production is anticipated?, in: Proceedings of ETCE/OMAE Joint Conference, New Orleans, LA, Feb. 14-17, 2000.

[11] A. Gnanavelu, N. Kapur, A. Neville, J.F. Flores, An integrated methodology for predicting material wear rates due to erosion, Wear 267 (2009) 1935-1944.

[12] X. Chen, B.S. McLaury, S.A. Shirazi, A comprehensive procedure to estimate erosion in elbows for gas/liquid/sand multiphase flow, ASME J. Energy Res. Tech. 128 (2006) 1-9.

[13] X. Chen, B.S. McLaury, S.A. Shirazi, Application and experimental validation of a computational fluid dynamics (CFD) based erosion prediction model in elbows and plugged tees, J. Comput. Fluids 33 (2004) 1251-1272.

[14] R.J.K. Wood, T.F. Jones, J. Ganeshalingam, N.J. Miles, Comparison of predicted and experimental erosion estimates in slurry ducts, Wear 256 (2004) 937-947.

[15] J. Fan, X. Yao, K. Cen, Experimental and numerical investigation of a new method for protecting bends from erosion in gas-particle flow, Wear 251 (2001) 853-960.

[16] X. Chen, B.S. McLaury, S.A. Shirazi, Numerical and experimental investigation of the relative erosion severity between plugged tees and elbows in dilute gas/solid two-phase flow, Wear 261 (2006) 715-729.

[17] M.H. Wang, C. Huang, K. Nandakumar, P. Minev, J. Luo, S. Chiovelli, Computational fluid dynamics modeling and experimental study of erosion in slurry jet flows, Int. J. Comput. Fluid Dynamics 23 (2) (2009) 155-173.

[18] ANSYS-CFX Modeling Guide 12.0, 2009.

[19] M. Pepple, Benchmark data for dilute, liquid-solid turbulent flow in the viscous, transitional and collisional flow regimes, in: 7th International Conference on Multiphase Flow, ICMF 2010, Tampa, FL, May 30-June 4, 2010.

[20] M. Chiesa, V. Mathiesen, J.A. Melheim, B. Halvorsen, Numerical simulation of particulate flow by the Eulerian-Lagrangian and the Eulerian-Eulerian approach with application to a fluidized bed, Computers \& Chemical Engineering 29 (2) (2005) 291-304.

[21] S. Lain, M. Sommerfeld, Euler/lagrange computations of pneumatic conveying in a horizontal channel with different wall roughness, Powder Technology 184 (2008) 76-88.

[22] C.A.J. Fletcher, Industrial CFD short course, Course Lecture Notes, University of New South Wales, June 27-July 1, 1994.

[23] G.J. Brown, Erosion prediction in slurry pipeline tee-junctions, Applied Mathematical Modeling 26 (2002) 155-170.

[24] D.R. Kaushal, T. Thinglas, Y. Tomita, S. Kuchii, H. Tsukamoto, CFD modeling for pipeline flow of fine particles at high concentration, International Journal of Multiphase Flow 43 (2012) 85-100.

[25] D. Thévenin, (Hrsg.): Flow through geometries, affected by friction forces [Online], July 2012, http://www.uni-agdeburg.de/isut/LSS/Lehre/Arbeitsheft/ VIII.pdf.

[26] D.A. Gorham, A.H. Kharaz, The measurement of particle rebound characteristics, Powder Technology 112 (2000) 193-202.

[27] G. Grant, W. Tabakoff, An Experimental Investigation of the Erosive Characteristics of 2024 Aluminum Alloy, Research report, Cincinnati University, June 1973.

[28] I. Finnie, Erosion of surface by solid particles, Wear 3 (1960) 87-103.

[29] C. Huang, S. Chiovelli, P. Minev, J. Luo, K. Nandakumar, A comprehensive phenomenological model for erosion of materials in jet flow, Powder Technology 187 (2008) 273-279.

[30] W. Tabakoff, R. Kotwal, A. Hamed, Erosion study of different material by coal ash particles, Wear 52 (1979) 161-170. 